\title{
Inhibitory Effects of Oyster Shell on the Spathe "Greenback" of Anthurium andraeanum Lind.
}

\author{
Xia Chun-hua ${ }^{1}$, Chen Yi-wei ${ }^{2}$, Chen Jian-hua ${ }^{*, 1}$ \\ ${ }^{*, 1}$ College of Forestry, Central South University of Forestry and Technology, Changsha, Hunan, 410004 China \\ ${ }^{2}$ Department of Landscape Architecture, Guangdong Ocean University, Zhanjiang, Guangdong, 524088 China
}

\begin{abstract}
Anthurium andraeanum Lind. is an important tropical flower. However, the spathe of $A$. andraeanum develops a "greenback" under low-light conditions. This study aimed to evaluate the use of oyster shell supplementation as a cultivation technique for inhibiting the spathe "greenback" of $A$. andraeanum under low-light conditions. Appropriate calcium from micro-dissolution of oyster shell can improve the activity of phenylalanine ammonia lyase (PAL) which is positively correlated with the anthocyanin content. Using regression models and response surface methodology (RSM), the relationships between oyster shell fragments and the anthocyanin content were determined. The results showed that the solubility of oyster shells increased with the increase in fragment weight, $\mathrm{C}$, and time, $\mathrm{T}$ at $\mathrm{pH}$ 5.9. In oyster shell substrate, cultivation of $A$. andraeanum under low-light conditions (less than $220 \mu \mathrm{mol} \cdot \mathrm{m}^{-2} \cdot \mathrm{s}^{-1}$ ) at $\mathrm{pH} 5.9$, regression analysis showed that the PAL activity in pedicels of $A$. andraeanum first increased and then decreased with the increase in oyster shell fragment weight $\mathrm{C}$, and the $286 \mathrm{mg}$ oyster shell fragments greatly increased the PAL activity of $A$. andraeanum pedicels within 8 weeks (w). The $286 \mathrm{mg}$ oyster shell fragments significantly increased the anthocyanin content in $A$. andraeanum spathes under weak-light conditions within $8 \mathrm{~h}$, and the soluble sugar content reached the maximum value at 15 weeks as well, together with the pedicel diameter, soluble sugar and water content, thus inhibiting the spathe "greenback" of $A$. andraeanum.
\end{abstract}

\section{Introduction}

Anthurium andraeanum Lind. is an important tropical flower variety ${ }^{[1,2]}$. Current research shows that the decrease of light intensity caused by excessive shading or prolonged low temperature and rainy periods in bagasse facility cultivation will lead to the occurrence of "greenback" symptoms in the spathe in which a red to green color gradually extends from the base of the spathe to the tip ${ }^{[3]}$, and the quality of flowers is significantly reduced $^{[4]}$.

Anthocyanin is known to be an extremely important chemical component in red flowers, and its content is also one of the key factors determining the color of A. andraeanum spathes. Considerable research has proven that the activity of PAL is positively correlated with the content of anthocyanin, and calcium can replace light and hormones to promote PAL activity ${ }^{[5]}$. Higaki et al. found that the greenback phenomenon was highly correlated with the calcium content in A. andraeanum plants, and appropriate exogenous calcium supplementation could significantly alleviate the symptoms ${ }^{[6,7]}$.

Oyster shells, massively deposited on the seashore, are a solid waste byproduct of the mariculture industry and are composed of more than $90 \%$ calcium carbonate, which is not easily dissolved under natural conditions, thus providing a valuable $\mathrm{Ca}$ resource ${ }^{[1]}$. Calcium carbonate can provide a good source of exogenous $\mathrm{Ca}$ in the soilless cultivation of $A$. andraeanum and can be used in the supplement ${ }^{[8]}$.

Calcium carbonate, the main component of oyster shells, is a potential long-term exogenous calcium material that micro-dissolves at a suitable $\mathrm{pH}$ value and can achieve a similar effect of calcium supplementation. An appropriate $\mathrm{pH}$ value and oyster shell fragment size are key to overcome the greenback symptoms of $A$. andraeanum under low-light conditions.

The study of oyster shells supplementation of $\mathrm{Ca}$ in the cultivation of $A$. andraeanum has not been previously investigated. This paper aimed to test the use of oyster shells supplementation of $\mathrm{Ca}$ for inhibiting the spathe greenback of $A$. andraeanum by (1) determining the effect of different sizes of oyster shell fragments, which lead to $\mathrm{Ca}$ micro-dissolution and increased PAL activity; (2) evaluating the effects of oyster shell fragment mass and cultivation time on the pedicel diameter, $\mathrm{Ca}^{2+}$ content and PAL activity in the pedicles; and (3) determining the changes in the soluble sugar, water content, and anthocyanin content in the spathe with oyster shell supplementation.

\footnotetext{
* corresponding author's e-mail: 10542022@qq.com
} 


\section{Materials and methods}

\subsection{Materials}

Three-year-old $A$. andraeanum 'Tropical' was grown in a 5-L flow aquarium using a general nutrient solution for $A$. andraeanum supplemented with oyster shell fragments (one plant per box). Five-centimeter-long flower branches were obtained with no mechanical damage and no pests or diseases, from which the pedicels were used for the determination of $\mathrm{Ca}$, PAL and pedicel diameter, while the spathe was used for determination of the anthocyanin content, the soluble sugar content and water content determination. The oyster shells were immersed in $0.1 \%$ hydrochloric acid solution for $10 \mathrm{~h}$, and then the oyster shells were dried naturally. The oyster shells were crushed using a grinder and then screened. Finally, the required oyster shell fragments were obtained.

\subsection{Method}

\subsubsection{Dissolution test method of oyster shell with different weights treated for different times}

Based on a previous test result ( $\mathrm{pH} 5.9$, (Xia \& Chen, 2019), $31.25,62.5,125,250$, and $500 \mathrm{mg}$ ) oyster shell fragments were selected as experimental materials and were soaked in 5-L phosphoric acid buffer flow aquariums at $\mathrm{pH}$ 5.9. The residual weight of the oyster shell was measured regularly (every $1 \mathrm{~h}, 3 \mathrm{~h}, 5 \mathrm{~h}, 7 \mathrm{~h}, 9 \mathrm{~h}$ ) and recorded separately. Solubility of oyster shells under different weight, $\mathrm{C}$, and time, $\mathrm{T}$, treatments was recorded and repeated three times.

\subsubsection{Test method for cultivation of $A$. andraeanum with 286 mg oyster shell fragments as a substrate}

In 286-mg oyster shell fragment soilless culture of $A$. andraeanum with a general nutrient solution at $\mathrm{pH} 5.9^{\text {[9], }}$ the Ca content, PAL activity, diameter of the pedicel, and anthocyanin, soluble sugar and water contents of the spathe were determined and repeated three times under low-light conditions ${ }^{[5]}\left(220 \mu \mathrm{mol} \cdot \mathrm{m}^{-2} \cdot \mathrm{s}^{-1}\right)$ at different times $(4,6,8,10,12$ weeks).

\subsubsection{Oyster shell supplementation effect on PAL and flower quality of $A$. andraeanum}

The oyster shell fragments were combined with the Anthurium general nutrient solution (the nutrient solution was changed once a week). The extraction and determination of PAL used the method of OUYANG G.C. (1985) ${ }^{[10]}$. The supernatant was measured at $\mathrm{OD}_{290}$ with an ultraviolet spectrophotometer. The determination of the anthocyanin content followed the method of the East China Normal University Biological Department (1980) [11]. The filtrate was filtered and measured spectrophotometrically at $\mathrm{OD}_{530}$. The relative concentration unit of the anthocyanins was expressed as a factor of 10. Extraction and determination of soluble sugars followed the anthrone-sulfuric acid method. Determination of the water content was based on the drying method.

\subsubsection{Data analysis}

The data were processed using Microsoft Excel 2013 and were analyzed using SPSS Statistics 20.0 (IBM Corp., Armonk, NY, USA). Using the response surface methodology (RSM), the second-order polynomial equation $y=b_{0}+b_{1} x_{1}+b_{2} x_{2}+b_{3} x_{1} x_{2}+b_{4} x_{1}^{2}+b_{5} x_{2}^{2}$ was used to analyze the results of each index in a complex factor and multi-level test. The fitted polynomial equation was then illustrated using three-dimensional surface plots to visualize the relationships between the responses of the variables.

\section{Results and Analysis}

\subsection{Effects of Fragment Weight, C $(\mathrm{mg})$, on the Dissolution Time of Oyster Shells}

The dissolution tests of oyster shells at different weights, $\mathrm{C}$, of $31.25,62.5,125,250$ and $500(\mathrm{mg})$ were carried out at a $\mathrm{pH}$ value of 5.9. The solubility of oyster shells of different weights, $\mathrm{C}$, at different treatment times, $\mathrm{T}$, was determined as shown in Table 1.

Table 1. Solubility analysis of oyster shell (OS) fragments with different weights, $\mathrm{C}(\mathrm{mg})$, treated for different times, $\mathrm{T}(\mathrm{h})$

\begin{tabular}{cccccc}
\hline $\begin{array}{c}\text { OS } \\
\text { Content C } \\
(\mathrm{mg})\end{array}$ & $1 \mathrm{~h}$ & $3 \mathrm{~h}$ & $5 \mathrm{~h}$ & $7 \mathrm{~h}$ & $9 \mathrm{~h}$ \\
\hline 31.25 & 0.023 & 0.025 & 0.025 & 0.026 & 0.025 \\
62.5 & 0.028 & 0.027 & 0.028 & 0.029 & 0.028 \\
125 & 0.031 & 0.033 & 0.032 & 0.034 & 0.034 \\
250 & 0.036 & 0.036 & 0.037 & 0.036 & 0.037 \\
500 & 0.045 & 0.047 & 0.047 & 0.048 & 0.047 \\
\hline
\end{tabular}

According to the regression analysis in Table 1, as shown in Figure 1, the solubility of oyster shells increased with the increase in fragment weight, $\mathrm{C}$, and time, $\mathrm{T}$. The larger the fragment (weight) and the longer the time, the higher the solubility. When $\mathrm{C}=855.2619$ (mg) and $\mathrm{T}=5.8351(\mathrm{~h})$, the solubility of the oyster shell reached a maximum value of $0.0519 \pm 0.0041(\mathrm{mg})$. The results showed that the solubility of the oyster shell differed significantly with the fragment weight $\mathrm{C}$ and time $\mathrm{T}$ $\left(\mathrm{F}=64.02 * *, \mathrm{~F}_{0.01}=4.1708, \mathrm{~F}>\mathrm{F}_{0.01}\right)$. 


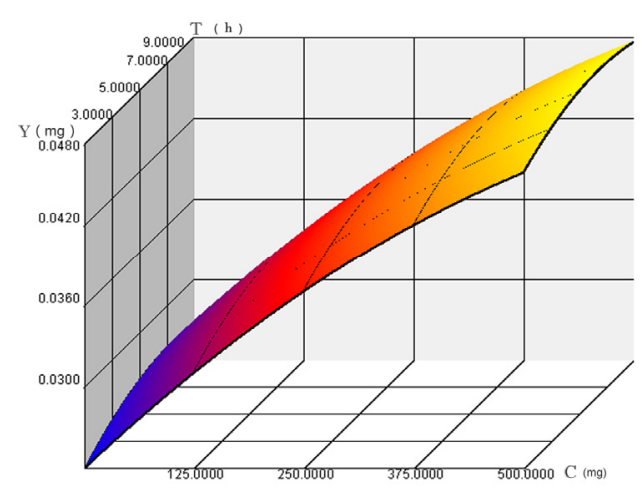

Figure 1. Solubility of oyster shell fragments treated with different weight $\mathrm{C}(\mathrm{mg})$ and time $\mathrm{T}(\mathrm{h})$

ydissolution $=0.02149+0.00006405 \mathrm{C}+0.00102 \mathrm{~T}-0.000000267 \mathrm{CT}-$ $0.00000003653 \mathrm{C}^{2}-0.00006786 \mathrm{~T}^{2}(\mathrm{~F}=64.02 * *)$

When $\mathrm{C}=855.2619(\mathrm{mg}), \mathrm{T}=5.8351(\mathrm{~h})$, the solubility reached a maximum value of $0.0519 \pm 0.0041(\mathrm{mg})$.

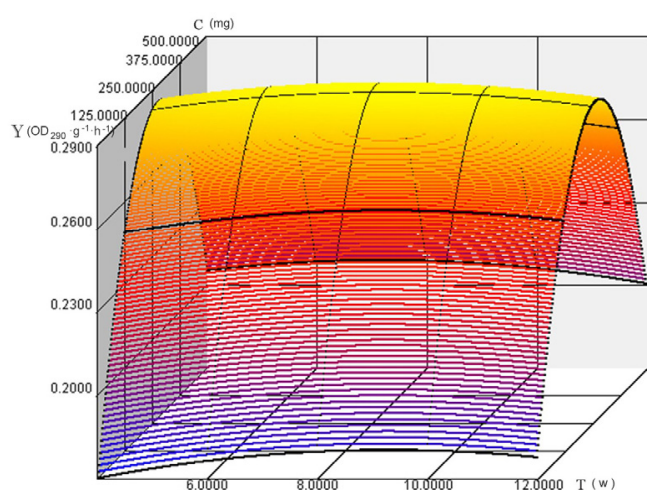

Figure 2. Effects of oyster shell fragments quality $\mathrm{C}(\mathrm{mg})$ and time $\mathrm{T}(\mathrm{w})$ treatment on PAL $\left(\mathrm{OD}_{290} \cdot \mathrm{g}^{-1} \cdot \mathrm{h}^{-1}\right)$ activity of the pedicle in Anthurium

У PAL $=0.1169+0.006827 \mathrm{~T}+0.00104 \mathrm{C}-0.000003328 \mathrm{TC}$ $-0.0003607 \mathrm{~T}^{2}-0.000001772 \mathrm{C}^{2}\left(\mathrm{~F}=4.1232^{*}\right)$

When $\mathrm{T}=8.1438(\mathrm{w}), \mathrm{C}=286.07(\mathrm{mg})$, the content of PAL reached a maximum of $0.2936 \pm 0.0838\left(\mathrm{OD}_{290} \cdot \mathrm{g}^{-1} \cdot \mathrm{h}^{-1}\right)$.

\subsection{Effects of oyster shell cultivation on PAL activity in pedicels of $A$. andraeanum, with different $C(\mathrm{mg})$ and $T(\mathrm{w})$ treatments}

The activity of PAL in pedicels of A. andraeanum cultivated under low-light conditions $\left(220 \mu \mathrm{mol} \cdot \mathrm{m}^{-2} \cdot \mathrm{s}^{-1}\right)$ was determined by applying the general nutrient solution of the oyster shell substrate culture. The effects of C $(\mathrm{mg})$ and time $\mathrm{T}(\mathrm{w})$ treatments on the activity of PAL in pedicels were studied.

Regression analysis showed that with the increase in oyster shell fragment weight C, PAL activity in pedicels of $A$. andraeanum increased first and then decreased (Fig. 2). When $\mathrm{C}=286(\mathrm{mg})$ and $\mathrm{T}=8.1(\mathrm{w})$, the activity of PAL reached the maximum value of $0.2936 \pm 0.0838$ $\left(\mathrm{OD}_{290} \cdot \mathrm{g}^{-1} \cdot \mathrm{h}^{-1}\right)$; when $\mathrm{C}$ exceeded $286 \mathrm{mg}$, the activity of PAL decreased if the time were prolonged. The possible reason was that the longer the time, the higher the cumulative calcium content, which would inhibit the activity of PAL, resulting in a decrease in the PAL activity. Statistical analysis showed that there were significant differences in PAL activity between the effects of the oyster shell fragment weight $\mathrm{C}$ and time $\mathrm{T}$ $\left(\mathrm{F}=4.1232 *, \mathrm{~F}_{0.05}=2.7401, \mathrm{~F}>\mathrm{F}_{0.05}\right)$.

\subsection{Determination of Related Index Contents of the Flower Quality of A. andraeanum}

The effects of $286 \mathrm{mg}$ oyster shell fragments on the flower quality of $A$. andraeanum cultivated under low-light conditions $\left(220 \mu \mathrm{mol} \cdot \mathrm{m}^{-2} \cdot \mathrm{s}^{-1}\right)$ at $\mathrm{pH} 5.9$ were compared by measuring the change in the diameter of the pedicels, the water content, the soluble sugar and the anthocyanin content in spathes of $A$. andraeanum (Table 2).

Table 2. Effect of $\mathrm{T}(\mathrm{w})$ treatment at different times on the quality of $A$. andraeanum flowers

\begin{tabular}{cccccc}
\hline & $4 \mathrm{w}$ & $6 \mathrm{w}$ & $8 \mathrm{w}$ & $10 \mathrm{w}$ & $12 \mathrm{w}$ \\
\hline $\begin{array}{c}\text { Pedicel diameter } \\
(\mathrm{cm})\end{array}$ & 0.28 & 0.32 & 0.36 & 0.38 & 0.38 \\
$\begin{array}{c}\text { Soluble sugar } \\
\left(\mathrm{mg} \cdot 100 \mathrm{~g}^{-1} \mathrm{Fw}\right)\end{array}$ & 0.312 & 0.386 & 0.453 & 0.514 & 0.537 \\
$\begin{array}{c}\text { Anthocyanin } \\
\left(\mathrm{OD}_{530}\right)\end{array}$ & 0.680 & 0.675 & 0.754 & 0.783 & 0.874 \\
Water content $(\%)$ & 0.84 & 0.81 & 0.77 & 0.80 & 0.78 \\
\hline
\end{tabular}

\subsubsection{Changes in pedicel diameter of $A$. andraeanum cultivated with oyster shell}

The regression analysis in Table 2 showed that with the increase in $\mathrm{T}$, the effect of $\mathrm{T}(\mathrm{w})$ treatment at different times on the pedicel diameter of $A$. andraeanum increased initially and then slowly decreased. The experimental results in Figure 3 show that when $\mathrm{r}=0.9969$, there is a highly significant relationship between the pedicel diameter and the treatment time $\left(\mathrm{F}=163.5^{* *}, \mathrm{~F}_{0.01}=99.00, \mathrm{~F}>\mathrm{F}_{0.01}\right)$, indicating that the increase in the pedicel diameter with the increase in time was very significant, but when $\mathrm{T}=11.64(\mathrm{w})$, the pedicel diameter had a maximum value of $0.3819 \pm 0.0077(\mathrm{~cm})$.

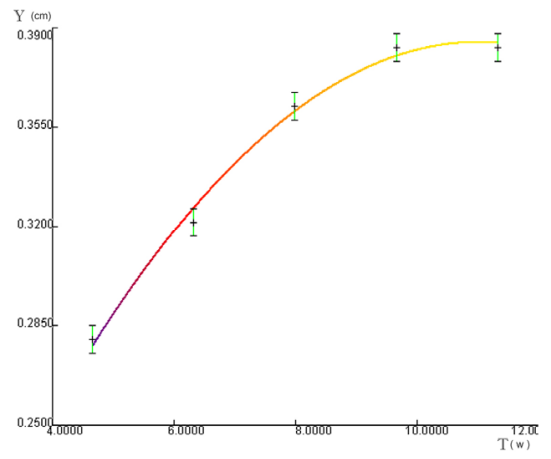

Figure 3. Changes in pedicel diameter under $A$. andraeanum cultivated with oyster shell

$\mathrm{y}_{\text {pedicel diameter }}=0.14+0.0415 \mathrm{~T} \pm 0.00178 \mathrm{~T}^{2}\left(\mathrm{~F}=163.5^{* *}\right)$

When $\mathrm{T}=11.64(\mathrm{w})$, the pedicel diameter reached the maximum of $0.3819 \pm 0.0077(\mathrm{~cm})$. 


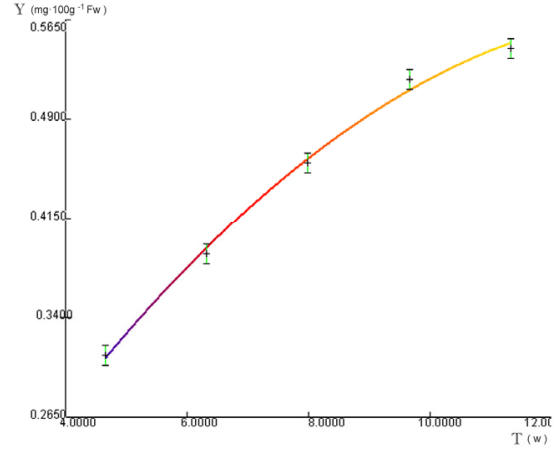

Figure 4. Changes in soluble sugar content in spathe of $A$. andraeanum cultivated with oyster shell

$$
\mathrm{y}_{\text {sugar }}=0.101+0.0597 \mathrm{~T} \pm 0.00192 \mathrm{~T}^{2}\left(\mathrm{~F}=306.6^{* *}\right)
$$

When $\mathrm{T}=15.5(\mathrm{w})$, the soluble sugar content reached the maximum value of $0.5641 \pm 0.0120\left(\mathrm{mg} \cdot 100 \mathrm{~g}^{-1} \mathrm{Fw}\right)$

\subsubsection{Changes in the Soluble Sugar Content in Spathes of $A$. andraeanum Cultivated with Oyster Shell}

The regression analysis in Table 2 showed that the effect of different times on the soluble sugar content in the spathe of $A$. andraeanum showed an increasing trend with the increase in time T. The results in Figure 4 show that when $r=0.9983$, the soluble sugar content in the spathe has a very significant relationship with the treatment time $\left(\mathrm{F}=306.6^{* *}, \quad \mathrm{~F}_{0.01}=99.00, \quad \mathrm{~F}>\mathrm{F}_{0.01}\right)$, indicating that the soluble sugar content of the spathe increased significantly with the increase in time, but when $\mathrm{T}=15.4926(\mathrm{w})$, the soluble sugar content of the spathe had a maximum value of $0.5641 \pm 0.0120$ $\left(\mathrm{mg} \cdot 100 \mathrm{~g}^{-1} \mathrm{FW}\right)$.

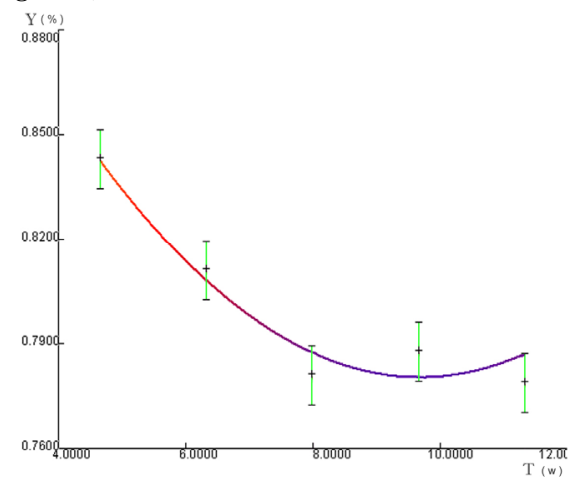

Figure 5. Changes of water content in spathe of $A$. andraeanum cultivated with oyster shell

$\mathrm{y}_{\text {water content }}=0.942-0.0322 \mathrm{~T}+0.0016 \mathrm{~T}^{2}(\mathrm{~F}=3.1)$

When $\mathrm{T}=10.02(\mathrm{w})$, the water content had the minimum value of $0.7806 \pm 0.0306(\%)$.

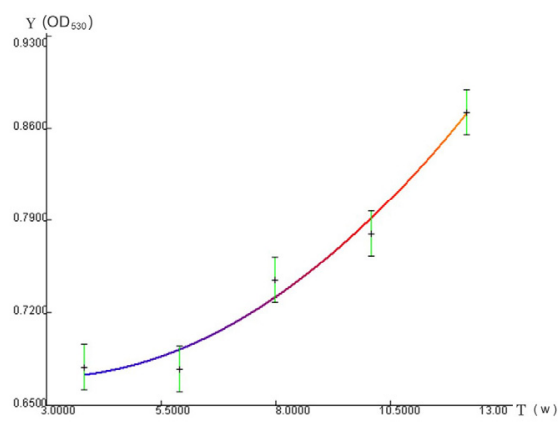

Figure 6. Effects of $\mathrm{T}(\mathrm{w})$ treatment on anthocyanin $\mathrm{OD}_{530}$ content of spathe in A. andraeanum

$$
\begin{gathered}
\text { Yanth }=0.6967 \pm 0.01577 \mathrm{~T}+0.002535 \mathrm{~T}^{2}(\mathrm{~F}=28.5261 * *) \\
\text { When } \mathrm{T}=3.1099(\mathrm{w}), \text { the content of anthocyanin was } \\
0.6723 \pm 0.0342\left(\mathrm{OD}_{530}\right) .
\end{gathered}
$$

\subsubsection{Changes in the Water Content in the Spathe of A. andraeanum Cultivated with Oyster Shell}

The regression analysis in Table 2 showed that the effect of the $\mathrm{T}(\mathrm{w})$ treatment at different times on the water content of the $A$. andraeanum spathe showed a downward trend with the increase in the treatment time. The results in Figure 5 show that when $r=0.8695$, the water content of the spathe had no significant relationship with the treatment time $\left(\mathrm{F}=3.1, \mathrm{~F}_{0.05}=19.00\right.$, $\mathrm{F}<\mathrm{F}_{0.05}$ ), indicating that the water content of the spathe did not increase significantly with the increase in time. However, when $\mathrm{T}=10(\mathrm{w})$, the water content of the spathe had a minimum value of $0.7806 \pm 0.0306(\%)$, when the water content was the lowest, the sugar content increased significantly, and the pedicel diameter approached the maximum value, while the calcium content began to decrease, and the PAL activity reached the maximum.

\subsubsection{Changes in the water Content in the spathe of A. andraeanum cultivated with oyster shell}

The regression analysis in Table 2 showed that the effect of $\mathrm{T}$ on the anthocyanin content in the spathe showed an increasing trend with the increase in treatment time. The results in Figure 6 show that increased time was associated with increased anthocyanin accumulation $(r=0.9829)$, with a significant interaction detected between the anthocyanin content and treatment time $\left(\mathrm{F}=28.5261^{*}, \mathrm{~F}_{0.05}=19.00, \mathrm{~F}>\mathrm{F}_{0.05}\right)$. At $\mathrm{T}=3.1(\mathrm{w})$, the minimum anthocyanin content was $0.6723 \pm 0.0342$ $\left(\mathrm{OD}_{530}\right)$.

\section{Discussion and conclusion}

The solubility of oyster shells increased with the increase in fragments mass $\mathrm{C}$ and time $\mathrm{T}$. The larger the fragments and the longer the time, the larger the solubility. 
In oyster shell substrate, cultivation of $A$. andraeanum under low-light conditions (less than $\left.220 \mu \mathrm{mol} \cdot \mathrm{m}^{-2} \cdot \mathrm{s}^{-1}\right)$ at $\mathrm{pH} 5.9$, the PAL activity and anthocyanin content increased with time, and the soluble sugar content increased correspondingly. At 8 weeks, the activity of PAL reached its maximum, while at 15 weeks, the soluble sugar content reached its maximum, which resulted in a higher content of anthocyanin. This was similar to the conclusion of a previous ${ }^{[5]}$ study in which $\mathrm{Ca}^{2+}$ promoted PAL activity ${ }^{[12]}$.

Oyster shells have a natural multi-porous structure with adsorption and slow-release characteristics ${ }^{[8]}$ and can absorb N, P and other elements to stabilize the concentration of $\mathrm{N}$ and $\mathrm{P}$ in the rhizosphere environment of the substrate and provide sufficient nutrients for the synthesis of soluble sugar ${ }^{[13,14]}$. When $A$. andraeanum was cultivated using $286 \mathrm{mg}$ oyster shell fragments under low-light conditions at $\mathrm{pH} 5.9$ for 10 weeks, the water content of the spathe reached a minimum value, the pedicel diameter $(11 \mathrm{w})$ reached the maximum value, and the soluble sugar content (expected $15 \mathrm{w}$ ) reached the maximum value, thus overcoming the problem of photosynthate (mainly sugar) accumulation decline caused by insufficient light ${ }^{[15]}$. At the same time, the anthocyanin content of the spathe also showed a rapid upward trend, showing a positive synchronization with flower quality indicators. The reason might be the soluble sugars provide abundant precursors for anthocyanin synthesis, thus increasing the content of anthocyanin.

Oyster shell dissolution is determined by environmental acidity. The lower the $\mathrm{pH}$, the faster the dissolution and the greater the dissolution amount, and more $\mathrm{Ca}^{2+}$ is released. The PAL activity was closely related to $\mathrm{Ca}^{2+}$ content ${ }^{[5]}$, and its peak values were earlier than that of soluble sugar, but were indirectly related to anthocyanin synthesis, and anthocyanin content did not exhibit the maximum value at the end of the test period, indicating that the synthesis of anthocyanin was also affected by other factors ${ }^{[16]}$.

One of the main limiting factors for the decrease in the anthocyanin content in A. andraeanum is low-light intensity. In the soilless cultivation of $A$. andraeanum under low-light conditions (produced in tropical winter), using oyster shell fragments as exogenous calcium (and as the cultivation medium) could effectively improve the PAL activity of the pedicel and the anthocyanin content of the spathe, which not only alleviates the environmental pollution caused by abandoned oyster shells but also improves the planting benefit of $A$. andraeanum.

\section{Acknowledgements:}

This paper was funded by Guangdong Science and Technology Project "Inhibitory Effect of Soilless Culture Medium on Greenback in the Spathe of Anthurium andraeanum" (2013B020302007).

\section{Reference}

1. Elibox W. and Umaharan P. 2008. Morphophysiological characteristics associated with vase life of cut flowers of Anthurium. HortScience. 43(3):825-831.

2. Wang Y.T. 1999. Greenhouse performance of six potted Anthurium cultivars in a subtropical area. HortTechnology. 9(3):12

3. Aisu Gu, Wenfang Liu, Chao Ma, and Jin Cui, Richard J. Henny and Jianjun Chen. 2012. Regeneration of Anthurium andraeanum from leaf explants and evaluation of microcutting rooting and growth under different light qualities. HortScience. 47(1):88-92.

4. Wang Y., Liu, S., Tian X., Fu Y., Jiang X., Li Y., Wang G. 2018. Influence of light intensity on chloroplast development and pigment accumulation in the wild-type and etiolated mutant plants of Anthurium andraeanum 'Sonate'. Plant Signaling \& Behavior 13(8): 76.

5. Xia C.H., Cai S.Y. 2004. Effects of GA 3 and $\mathrm{Ca}^{2+}$ on anthocyanin content and PAL activity of pedicels in Anthurium andraeanum spathe. Acta Horticulturae Sinica 31(3): 343-346 [in Chinese].

6. Higaki T, Tasmussen H. P. and Carpenter W. J. 1980. Color breakdown in Anthurium spathes caused by calcium deficiency. J. Amer. Soc. Hort. Sci. 105(3): 441-444.

7. Wang L.L., Yang G.S., Li C.H. 2012. Physiological causes of the occurrence of "greenear" in the bud of Anthurium andraeanum in Hainan. Acta Horticulturae Sinica 39(5): 939-948 [in Chinese].

8. Miao Y.L., Hong P.Z., Song W.D. 2007. Preliminary study on preparation of slow-release nitrogen fertilizer from oyster shell powder. Journal of Guangdong Ocean University. 27(6): 86-88 [in Chinese].

9. Wang H.F. 1997. Soilless cultivation of flowers. Jindun Publishing House. Beijing [in Chinese].

10. Ouyang G.C. 1985. Determination of Phenylalanine Ammonia Lyase (PAL) Activity. p.191. See: Editor-in-chief of Shanghai Society of Plant Physiology. Handbook of plant physiology experiments. Shanghai Science and Technology Publishing House. Shanghai [in Chinese].

11. Editor-in-chief, Physiology Teaching and Research Group, Department of Biology, East China Normal University (ECNU). 1980. Instruction for plant physiology experiments. People's Education Publishing House. Beijing [in Chinese].

12. Avila-Rostant O., Lennon A.M., and Umaharan P. 2010. Spathe color variation in Anthurium andraeanum Hort. and its relationship to vacuolar pH. HortScience 45(12): 1768-1772.

13. Chang K.H., Wu R.Y., Chang G.P., Hsieh T.F., Chung R.S. 2012. Effects of nitrogen concentration 
on growth and nutrient uptake of Anthurium andraeanum Lind. cultivated in coir under different seasonal conditions. HortScience 47(4): 515-521.

14. Wang H.L. 1999. Effects of low temperature storage on sugar content, respiration rate and quality of Anthurium indicum. Plant Physiological Communication 35(6): 458-460 [in Chinese].

15. Higaki T., Imamura J. S., Paull R. E. 1992. N, P, and $\mathrm{K}$ rates and leaf tissue standards for optimum Anthurium andraeanum flower production. HortScience 27(8): 909-912.

16. Elibox W. and Umaharan P. 2008. Inheritance of major spathe colors in Anthurium andraeanum Hort. is determined by three major genes. HortScience. 43(3):787-791. 